\title{
Effect of Photolysis on Zirconium Amino Phenoxides for the Hydrophosphination of Alkenes: Improving Catalysis
}

\author{
Bryan T. Novas ${ }^{1}$, Jacob A. Morris ${ }^{1}$, Matthew D. Liptak ${ }^{1}$ and Rory Waterman 1 ,*
}

\begin{abstract}
A comparative study of amino phenoxide zirconium catalysts in the hydrophosphination of alkenes with diphenylphosphine reveals enhanced activity upon irradiation. The origin of improved reactivity is hypothesized to result from substrate insertion upon an $\mathrm{n} \rightarrow \mathrm{d}$ charge transfer of a $\mathrm{Zr}-\mathrm{P}$ bond in the excited state of putative phosphido $(\mathrm{Zr}-\mathrm{PR} 2)$ intermediates. TD-DFT analysis reveals the lowest lying excited state in the proposed active catalysts are dominated by a P $3 p \rightarrow \mathrm{Zr} 4 d$ MLCT, presumably leading to enhanced catalysis. This hypothesis follows from triamidoamine-supported zirconium catalysts but demonstrates the generality of photocatalytic hydrophosphination with $\mathrm{d}^{0}$ metals.
\end{abstract}

Keywords: Hydrophosphination; Photocatalysis; Zirconium; Phosphines

\section{Introduction}

Liptak, M.D.; Waterman, R. Effect of Photolysis on Zirconium Amido Phenoxides for the Hydrophosphination of Alkenes: Improving Catalysis.

Organophosphines have found extensive use in the areas of materials science, biology, agriculture, electronics, and especially, catalysis [1-7]. Despite their utility,
1 Department of Chemistry, University of Vermont, 82 University Place, Burlington, VT 05401, USA; Bryan.Novas@uvm.edu (B.T.N.); Jacob.Morris@uvm.edu (J.A.M.); Matthew.Liptak@uvm.edu (M.D.L)

* Correspondence: Rory.Waterman@uvm.edu responsible use of phosphorus is imperative as a result of dwindling supply [2,3,8]. Selective carbon-phosphorus bond formation has been an on-going focus of research for these reasons [4,9-14]. A wide range of phosphine chemistry has been developed, with metal catalyzed hydrophosphination being one of the most economic avenues for P-C bond formation. Though significant progress has occurred [1,7,15-24], challenges remain for this transformation, with catalyst and substrate scope being two key avenues for improvement $[1,15,25-30]$.

Photolysis has been demonstrated to increase the activity of triamidoamine zirconium compounds for hydrophosphination catalysis while also unlocking reactivity with previously inert substrates [31-33]. This methodology has been extended to other group 15 substrates, leading to improved hydroarsination catalysis with primary arsines [34]. Photolysis plays a key role in these reactions, where reactions are sluggish if not inactive under the strict exclusion of light [27,31,32,34-36]. Analysis by time-dependent density functional theory (TD-DFT) suggests the enhanced reactivity under photolysis is due to the population of a charge-transfer state that exhibits significant $\sigma^{*}$ character and 
weakening of the $\mathrm{Zr}-\mathrm{P}$ bond that allows more facile substrate insertion [31]. A question arose from the triamidoamine-supported zirconium studies, is this photocatalysis general? The particular geometry and frontier orbital arrangement of triamidoamine zirconium may result in exclusive photocatalytic activity. To test for general photocatalysis, other known hydrophosphination catalysts with different geometries and donor ligands must be screened.

Yao and coworkers reported a library of zirconium complexes bearing amino phenoxide ligands for the hydrophosphination of alkenes and heterocumulenes [37]. These compounds gave modest turnovers of the hydrophosphination of several styrene derivatives with diphenylphosphine under ambient conditions and low catalyst loadings [37], and a similar study was reported with primary phosphine substrates [38]. Their successful zirconium catalysts with pseudo-octahedral geometries and $\mathrm{N}_{\mathrm{x}} \mathrm{O}_{\mathrm{y}}$ donor ligand sets were ideal to test hypothesis that photocatalytic enhancement is general. Yao and coworkers' most active hydrophosphination catalyst bearing an $\mathrm{N}_{2} \mathrm{O}\left(\mathrm{N}_{2} \mathrm{O}=\mathrm{O}-2,4\right.$ - $\mathrm{Bu}_{2} \mathrm{C}_{6} \mathrm{H}_{2}-$ 6- $\left.\mathrm{CH}_{2} \mathrm{~N}\left(\mathrm{CH}_{2} \mathrm{CH}_{2} \mathrm{NMe}_{2}\right) \mathrm{CH}_{2}-2-\mathrm{MeO}-3,5-\mathrm{Bu}_{2} \mathrm{C}_{6} \mathrm{H}_{2}\right)$ donor set was chosen along with a less active analog bearing an $\mathrm{N}_{2} \mathrm{O}_{2}\left(\mathrm{~N}_{2} \mathrm{O}_{2}=1,4-\right.$ bis $\left(\mathrm{O}-2,4-{ }^{-} \mathrm{Bu}_{2}-6-\mathrm{CH}_{2}\right)$ piperazine $)$ donor set (Figure 1).

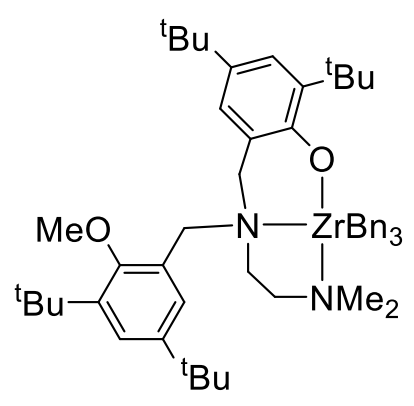

(1)

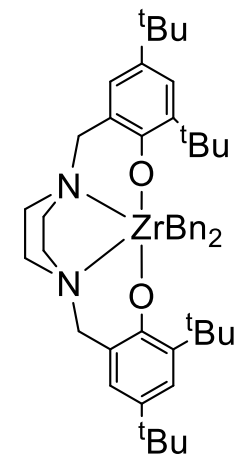

(2)

Figure 1. Molecular structure of compounds 1 and 2.

\section{Results and Discussion}

\subsection{Photocatalytic Hydrophosphination}

Styrene was treated with 1 equiv. of $\mathrm{Ph}_{2} \mathrm{PH}$ and $5 \mathrm{~mol} \%$ of $\left(\mathrm{N}_{2} \mathrm{O}\right) \mathrm{ZrBn}_{3}(\mathbf{1})$ at ambient temperature under visible light irradiation to afford $83 \%$ conversion to the corresponding hydrophosphination product in $2 \mathrm{~h}$ (Table 1, Entry 1). Performing the same reaction under ambient light provided $8 \%$ conversion after $2 \mathrm{~h}$ (Table 1, Entry 2 ) and 87\% conversion after a period of $24 \mathrm{~h}$ (Table 1, Entry 4). Reactions run in the dark showed severely reduced product formation, with scarcely observable $(\sim 1 \%)$ product phosphine formed in $2 \mathrm{~h}$ (Table 1, Entry 3) and only 4\% conversion after $24 \mathrm{~h}$ (Table 1, Entry 5). Catalysis was also expanded to para- substituted styrenes. Reaction of 4-tert-butyl styrene with $\mathrm{Ph} 2 \mathrm{PH}$ under identical conditions led to $70 \%$ conversion of the product phosphine (Table 1, Entry 6). Treatment of 4-bromo styrene with $\mathrm{Ph}_{2} \mathrm{PH}$ under identical conditions gave 91\% 
conversion in $2 \mathrm{~h}$ (Table 1, Entry 7). Similar reactions were successful with non-styrene substrates. Hydrophosphination with 2,3-dimethyl butadiene resulted in $65 \%$ conversion in $2 \mathrm{~h}$ (Table 1, Entry 8). Methyl acrylate, a commonly active hydrophosphination substrate, gave $90 \%$ conversion to the hydrophosphination product under identical conditions (Table 1, Entry 9). Trans-chalcone, a typical model substrate in asymmetric hydrophosphination [29,30], showed $68 \%$ conversion in a modest $24 \mathrm{~h}$ period (Table 1 , Entry 10).

Table 1. Intermolecular hydrophosphination of alkenes and $\mathrm{Ph}_{2} \mathrm{PH}$ catalyzed by $\mathbf{1}$.

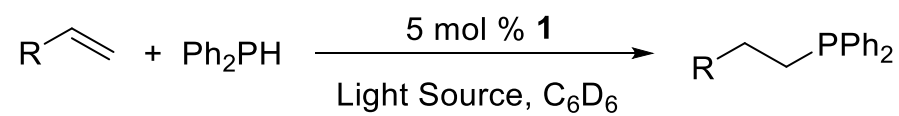

(n)

Greater conversions were observed, even at lower catalyst loadings, for all styrene substrates through photolysis, complementing the progress made by Yao and co-workers in identifying this compound for hydrophosphination catalysis [37]. It is clear from these results that photolysis can serve to improve hydrophosphination catalysis for $\mathbf{1}$ using secondary phosphines. 
Yao and co-workers demonstrated activity with primary phosphines as well [38]. In that report, neither $\mathbf{1}$ or $\mathbf{2}$ were used, but the reported catalysts resemble those investigated in the study and their prior work. Given the enhanced activity of $\mathbf{1}$ and $\mathbf{2}$ under photocatalytic conditions, expanding to primary phosphines was explored. Reaction of styrene with $\mathrm{PhPH}_{2}$ and $5 \mathrm{~mol} \%$ of $\mathbf{1}$ resulted in quantitative consumption of styrene at 2 $\mathrm{h}$ of irradiation (Table 2, Entry 1). The same reaction under ambient light resulted in $21 \%$ conversion (Table 2, Entry 2). Extending the reaction period to $24 \mathrm{~h}$ resulted in $69 \%$ conversion (Table 2, Entry 4). Performing this reaction in the dark resulted in a severely diminished $2 \%$ conversion after $2 \mathrm{~h}$ (Table 2, Entry 3 ) and $4 \%$ conversion after $24 \mathrm{~h}$ (Table 2, Entry 4). Low conversion under ambient light suggests a reason why 1 was not reported in Yao's 2018 study [38], but it affirms the impact of photolysis on $\mathrm{d}^{0}$ hydrophosphination catalysts.

Table 2. Intermolecular hydrophosphination of styrene and $\mathrm{PhPH}_{2}$ catalyzed by $\mathbf{1}$.

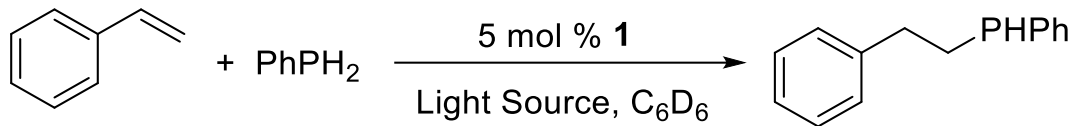

\begin{tabular}{llll}
\hline Entry & Light Source & Time & Conversion \\
\hline Product & Ambient & $2 \mathrm{~h}$ & $>99 \%$ \\
\hline APHPh & Ambient & $24 \mathrm{~h}$ & $2 \%$ \\
\hline
\end{tabular}


The change in geometry and lower relative reactivity of $\left(\mathrm{N}_{2} \mathrm{O}_{2}\right) \mathrm{ZrBn}_{2}(2)$ as compared to 1 prompted exploration under photocatalytic conditions. Reaction of styrene with $\mathrm{Ph}_{2} \mathrm{PH}$ and $5 \mathrm{~mol} \%$ of 2 resulted in 91\% product formation after $2 \mathrm{~h}$ (Table 3, Entry 1). Conversion under ambient light was behind, providing $12 \%$ conversion after $2 \mathrm{~h}$ (Table 3 , Entry 2), and 92\% conversion after an extended $24 \mathrm{~h}$ (Table 3, Entry 4). As expected, reactions run rigorously in the dark afforded barely detectable conversion after $2 \mathrm{~h}$ (Table 3, Entry 3), and 1\% conversion after $24 \mathrm{~h}$ (Table 3, Entry 5). Substituted styrenes showed a similar trend to $\mathbf{1}$. However, slightly greater conversions were observed under photolysis as compared to ambient light. A conversion of $88 \%$ was observed for reaction of 4-tert-butyl styrene (Table 3, Entry 6), and quantitative conversion was observed for reaction of 4-bromo styrene after $2 \mathrm{~h}$ (Table 3, Entry 4). Under the same conditions with 2,3-dimethyl butadiene as substrate, 66\% conversion was observed. (Table 3, Entry 6). Quantitative conversion was seen when using methyl acrylate as substrate (Table 3, Entry 7 ), and $83 \%$ conversion was observed with pro-chiral trans-chalcone over a period of $24 \mathrm{~h}$ (Table 3, Entry 8).

Table 3. Intermolecular hydrophosphination of alkenes and $\mathrm{Ph}_{2} \mathrm{PH}$ catalyzed by 2.

$$
\mathrm{R} \curvearrowright+\mathrm{Ph}_{2} \mathrm{PH} \underset{\text { Light Source, } \mathrm{C}_{6} \mathrm{D}_{6}}{\longrightarrow} \stackrel{5 \mathrm{~mol} \% 2}{\sim} \mathrm{PPh}_{2}
$$

Entry




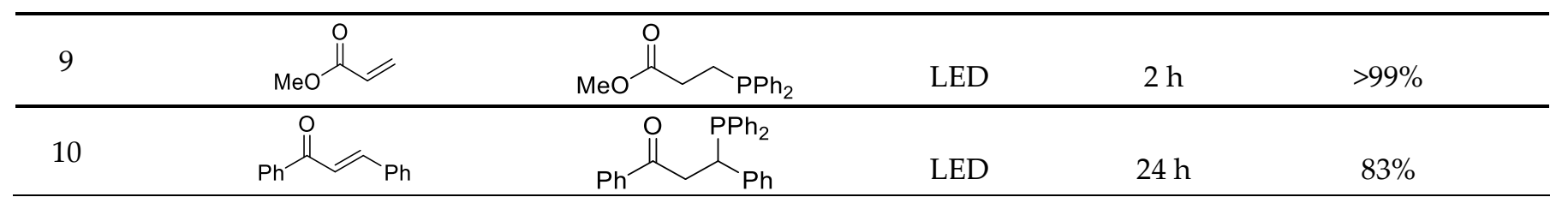

As with 1, the reactivity of 2 in hydrophosphination with $\mathrm{PhPH}_{2}$ was explored. 131 Reaction of styrene with $\mathrm{PhPH}_{2}$ and $5 \mathrm{~mol} \%$ of 2 resulted in quantitative conversion of styrene to product (Table 4, Entry 1). Using these conditions under ambient light availed 132 17\% conversion in $2 \mathrm{~h}$ (Table 4, Entry 2) and 76\% conversion in $24 \mathrm{~h}$ (Table 4, Entry 4). 133 Running this reaction in the absence of light reduced the conversion to $\sim 2 \%$ after $24 \mathrm{~h}$ 134 (Table 4, Entry 5).

Table 4. Intermolecular hydrophosphination of styrene and $\mathrm{PhPH}_{2}$ catalyzed by 2.<smiles>C=Cc1ccccc1</smiles>

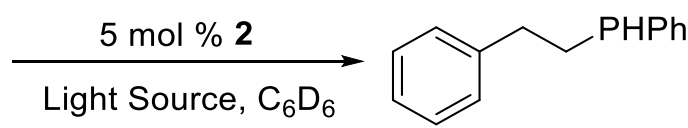

\begin{tabular}{|c|c|c|c|c|}
\hline Entry & Product & Light Source & Time & Conversion \\
\hline 1 & & LED & $2 \mathrm{~h}$ & $>99 \%$ \\
\hline 2 & & Ambient & $2 \mathrm{~h}$ & $17 \%$ \\
\hline 3 & & Dark & $2 \mathrm{~h}$ & $>1 \%$ \\
\hline 4 & & Ambient & $24 \mathrm{~h}$ & $76 \%$ \\
\hline 5 & & Dark & $24 \mathrm{~h}$ & $2 \%$ \\
\hline
\end{tabular}




\subsection{Computational Analysis}

Spectroscopic and computational analysis has indicated an $\mathrm{n} \rightarrow \mathrm{d}$ charge transfer in hydrophosphination catalysis using triamidoamine-supported zirconium which leads to improved reactivity as a result of promoted insertion [31]. It was previously hypothesized that pre-existing catalysts could be enhanced by photolysis, and this has been confirmed by experimental results using $\mathbf{1}$ and $\mathbf{2}$. To further elucidate whether enhanced catalysis is a result of accessing an excited state in potential intermediates where insertion is promoted, TD-DFT modeling was utilized.

All efforts to produce phosphido complexes of $\mathbf{1}$ and $\mathbf{2}$ failed, leading to the employment of the crystal structure of 2 to construct a structural model [39]. The geometry of the structural model was optimized using density functional theory (DFT) with the B3LYP functional and the def2-TZVP basis set. The modeling employed the RIJCOSX approximation and tight SCF convergence criteria. The conductor-like polarizable continuum model (CPCM) was used to define a solvent through its dielectric constant and refractive index. The root-mean-square deviation (RMSD) of the optimized geometry of $\mathbf{2}$ compared to the crystal structure was $0.813 \AA$. Visually, the DFT-optimized geometry has more exposed benzyl groups (Figure 2).
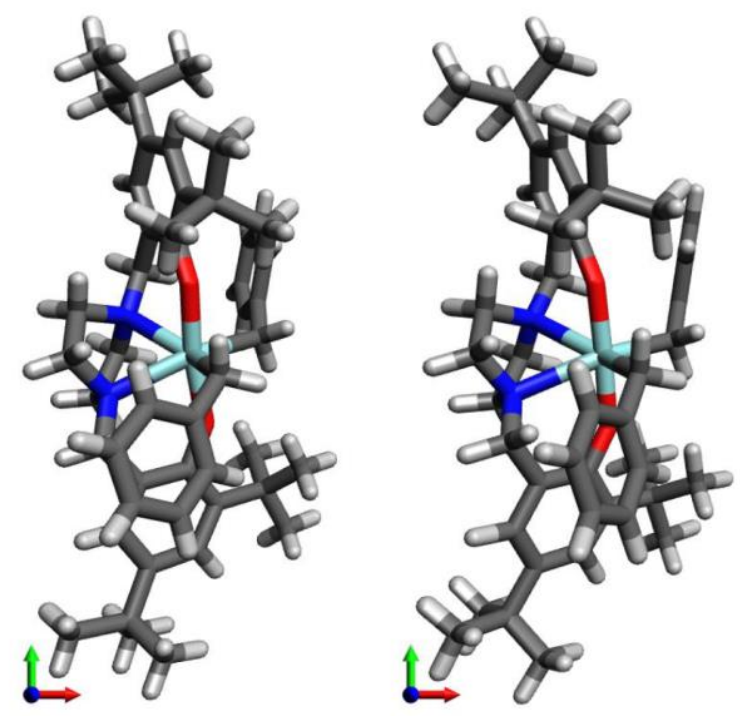

Figure 2. The crystal structure (left) and DFT-optimized geometry (right) of 2.

The electronic structure of $\mathbf{2}$ was probed via TD-DFT. The first ten electronic transitions were calculated with an expansion space of 60 vectors using the B3LYP functional and def2-TZVP basis set, again employing the RIJCOSX approximation and tight SCF convergence criteria. Solvent was simulated with the CPCM solvation model. The orca_mapspc was used to convolute the transitions through Gaussians with a full-width half-max (FWHM) of $1500 \mathrm{~cm}^{-1}$. This was compared with an experimental absorption spectrum of 2 in diethyl ether, revealing a low-energy, low-intensity shoulder and a higher-energy, higher-intensity peak around $30,000 \mathrm{~cm}^{-1}$ in both the experimental and predicted spectra (Figure 3). The predicted spectrum is slightly redshifted compared to the experimental 
spectrum; a common phenomenon that was also observed in the modeling of triamidoamine zirconium [31].

182
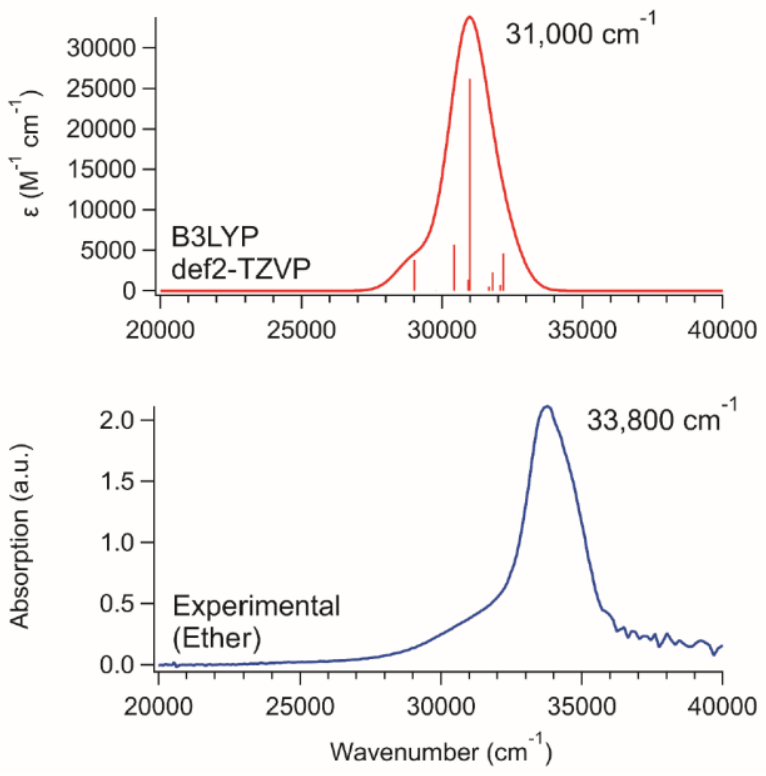

Figure 3. TD-DFT-predicted absorbance spectrum at the B3LYP/def2-TZVP level of theory in the gas phase for $\mathbf{2}$ (red spectrum) and experimental absorbance spectrum for $\mathbf{2}$ in diethyl ether (blue spectrum).

It is important to consider that from the absorbance spectra, B3LYP/def2-TZVP predicts a consistent electronic structure for 2 assuming the zirconium oxidation state and molecule charge doesn't change when forming the active catalyst $\left(2\left(\mathrm{PPh}_{2}\right)_{\mathrm{n}}\right)$. If this is the case, the computational model will still be accurate. However, we can't conclusively prove this without experimental spectra of the active catalyst.

Structural models of the active catalysts (hereafter $\mathbf{A}, \mathbf{B}$, and $\mathbf{A B}$ ) were prepared from the B3LYP-optimized geometry of $\mathbf{2}$ using the program Avogadro. Either one (A), the other $(\mathbf{B})$, or both (AB) benzyl substituents were replaced with $\mathrm{PPh}_{2}$ substituents. The geometry of A, B, and AB were optimized using DFT at the B3LYP/def2-TZVP level of theory, employing the RIJCOX approximation, tight SCF convergence criteria, and simulating benzene solvent using CPCM (Figure 4). 

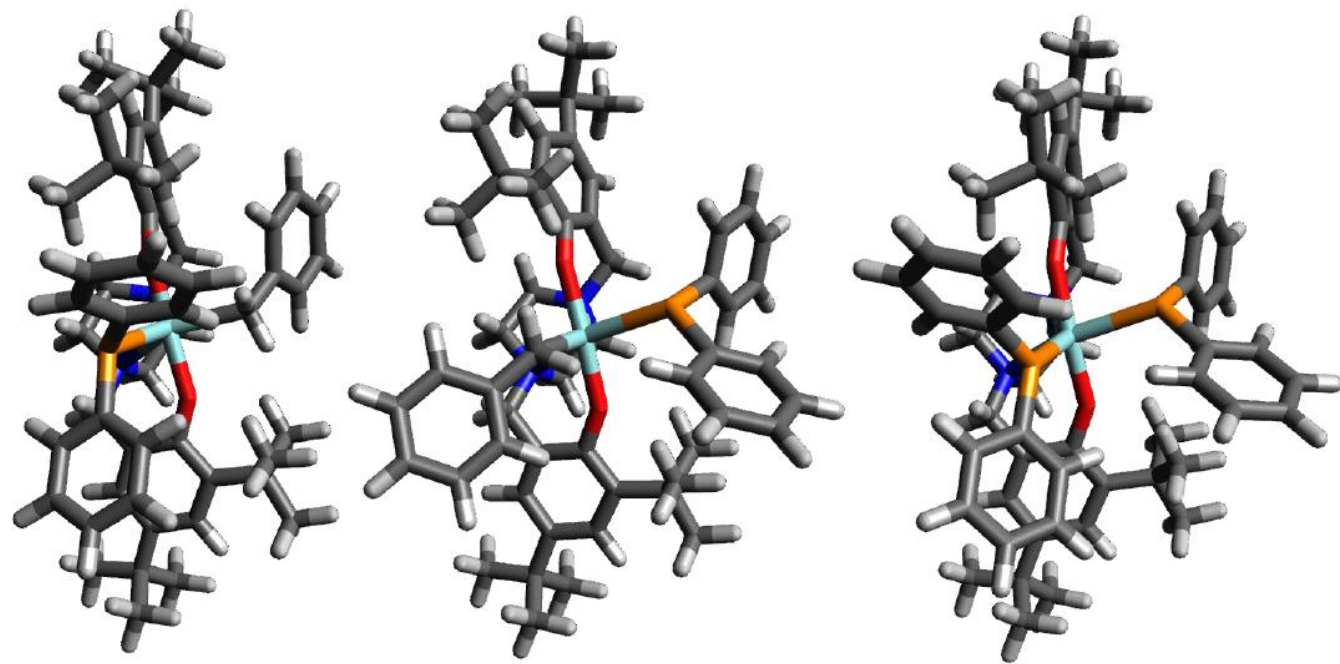

Figure 4. DFT optimized geometry of $\mathbf{A}$ (left), $\mathbf{B}$ (middle), and $\mathbf{A B}$ (right) at the B3LYP/def2-TZVP level of theory.

Geometry optimizations give a final Single Point Energy (SPE). The SPE is related to the number of atoms, and so only $\mathbf{A}$ and $\mathbf{B}$, which have the same number of atoms, can be compared. There is no energetic preference for replacing $\mathrm{Bn} \mathbf{A}$ or $\mathbf{B}$ with $\mathrm{PPh}_{2}$ over the other.

TD-DFT calculations at the B3LYP/def2-TZVP level of theory, with the RIJCOSX approximation, tight SCF convergence criteria, and simulating benzene with $\mathrm{CPCM}$ were carried out to probe the electronic transitions of compounds $\mathbf{A}, \mathbf{B}$, and $\mathbf{A B}$. Without experimental spectra, it cannot be conclusively stated that the computational electronic structure is consistent, but there is good reason to believe it would be. Regardless, the predicted absorbance spectra were mapped using orca_mapspc to convolute Gaussians with a FWHM of $1500 \mathrm{~cm}^{-1}$ (Figure in SI). The first 10 electronic transitions were calculated with an expansion space of 60 vectors.

It was hypothesized that excitation into a high-lying excited states is followed by relaxation to the lowest-lying excited state, following Kasha's Rule, from which catalysis was proposed to occur [31]. The lowest three excited states for compound $\mathbf{A}$ are dominated by transitions that exhibit donation from a P $3 p$ orbital to a $\mathrm{Zr} 4 d$ orbital, consistent with work using triamidoamine zirconium [31]. Excited states for compound $\mathbf{B}$ are largely the same, to the extent of having the same orbital numbers. In compound $\mathbf{A B}$, the lowest four excited states are primarily $\mathrm{P} \rightarrow \mathrm{Zr}$ donation, because of the second $\mathrm{PPh} 2$ moiety.

The charge and formal oxidation state of zirconium does not change when $\mathbf{2}$ becomes $\mathbf{A}, \mathbf{B}$, or $\mathbf{A B}$, and so it can be assumed that the computational model will remain accurate. In any active catalyst models (A, $\mathbf{B}$, or $\mathbf{A B})$, the lowest lying excited state-where chemistry is proposed to occur via Kasha's Rule-is dominated by a charge transfer from the $P$ $3 p$ orbital to the $\mathrm{Zr} 4 d$ orbital. This is a $\mathrm{P} \mathrm{n} \rightarrow \mathrm{Zr} d$ transition. Based on prior results [31], we can assume that this charge transfer is correlated with elongation of the $\mathrm{Zr}-\mathrm{P}$ bond in the lowest-lying excited state, thereby weakening the bond to facilitate insertion chemistry. This hypothesis is corroborated by our experimental results in photocatalytic hydrophosphination using $\mathbf{1}$ and $\mathbf{2}$. 
Irradiation serves to enhance intermolecular hydrophosphination catalysis with $\mathbf{1}$ and $\mathbf{2}$ for both secondary and primary phosphines. An accurate computational model of the electronic structure of $\mathbf{2}$ was determined. The lowest lying excited state in compounds $\mathbf{A}, \mathbf{B}$, and $\mathbf{A B}$ were found to be dominated by $\mathrm{P} \mathrm{n} \rightarrow \mathrm{Zr}$ d transitions, likely promoting insertion chemistry. In sum, these findings establish that photocatalytic hydrophosphination is not restricted to triamidoamine-supported zirconium, fivecoordinate zirconium, or nitrogen donors. It is general to other zirconium catalysts equipped with distinct geometries and donor ligand sets, and these results suggest that this enhancement may be broadly applicable to $\mathrm{d}^{0}$ metals though a similar mechanism.

\section{Synthetic, Spectroscopic, and Catalytic Methods}

All air-sensitive manipulations were performed according to a previously published literature procedure [31,32]. Diphenylphosphine was synthesized according to a modified literature procedure [40]. $\mathbf{1}$ and $\mathbf{2}$ were synthesized according to modified literature procedures $[37,39]$. All other chemicals were obtained from commercial suppliers and dried by conventional means.

NMR spectra were recorded with a Bruker AXR $500 \mathrm{MHz}$ spectrophotometer in benzene- $d_{6}$ solution and reported with reference to residual solvent signal $(\delta=7.16 \mathrm{ppm})$ in ${ }^{1} \mathrm{H}$ NMR spectra. Absorption spectra were recorded with an Agilent Technologies Cary 100 Bio UV-Visible Spectrophotometer (Santa Clara, California, USA) as ether solutions. $\left(\mathrm{N}_{2} \mathrm{O}_{2}\right) \mathrm{ZrBn} 2$ was excited between 700 and $200 \mathrm{~nm}$ and excitation slits were set to $2 \mathrm{~nm}$.

Hydrophosphination of alkenes were carried out in a PTFE-sealed J-Young style NMR tube charged with $0.1 \mathrm{mmol}$ alkene, $0.1 \mathrm{mmol}$ phosphine $\left(1.0 \mathrm{M}\right.$ benzene- $d_{6}$ solvent stock solution), and $5 \mathrm{~mol} \%$ of catalyst $\left(0.04 \mathrm{M}\right.$ benzene- $d_{6}$ stock solution). The solutions were reacted at ambient temperature for noted period under irradiation. The consumption of substrate to product were monitored by ${ }^{1} \mathrm{H}$ NMR and ${ }^{31} \mathrm{P}\left\{{ }^{1} \mathrm{H}\right\}$ NMR spectroscopy. Reaction run in new NMR tubes showed identical conversions as those run in reused, washed NMR tubes.

Supplementary Materials: The following are available online at www.mdpi.com/xxx.

Author Contributions: Conceptualization, B.T.N., R.W.; synthesis, B.T.N.; catalysis, B.T.N.; computation, J.A.M., M.D.L; draft preparation, B.T.N., J.A.M., R.W.; supervision, M.D.L., R.W.; funding acquisition, R.W. All authors have read and agreed to the published version of the manuscript.

Funding: This research was funded by the National Science Foundation through CHE-2101766.

Acknowledgments: The authors would like to thank Dr. Christine Bange for her seminal contributions in light-driven, zirconium-catalyzed hydrophosphination.

Conflicts of Interest: The authors declare no conflict of interest. The funders had no role in the design of the study; in the collection, analyses, or interpretation of data; in the writing of the manuscript, or in the decision to publish the results.

\section{References}

1. Bange, C.A.; Waterman, R. Challenges in Catalytic Hydrophosphination. Chem. Eur. J. 2016, 22, 12598-12605, 
2. Slootweg, J.C. Sustainable Phosphorus Chemistry: A Silylphosphide Synthon for the Generation of Value-Added Phosphorus Chemicals. Angew. Chem. Int. Ed. Engl. 2018, 57, 6386-6388, doi:10.1002/anie.201803692.

3. Falk Øgaard, A.; Brod, E. Efficient Phosphorus Cycling in Food Production: Predicting the Phosphorus Fertilization Effect of Sludge from Chemical Wastewater Treatment. J. Agric. Food. Chem. 2016, 64, 4821-4829, doi:10.1021/acs.jafc.5b05974.

4. Troev, K.D. Chapter 2 - Reactivity of P-H Group of Phosphines. In Reactivity of P-H Group of Phosphorus Based Compounds, Troev, K.D., Ed.; Academic Press: 2018; pp. 19-144.

5. Greenberg, S.; Stephan, D.W. Phosphines bearing alkyne substituents: synthesis and hydrophosphination polymerization. Inorg. Chem. 2009, 48, 8623-8631, doi:10.1021/ic9012284.

6. Kovacik, I.; Wicht, D.K.; Grewal, N.S.; Glueck, D.S.; Incarvito, C.D.; Guzei, I.A.; Rheingold, A.L. Pt(Me-Duphos)-Catalyzed Asymmetric Hydrophosphination of Activated Olefins: Enantioselective Synthesis of Chiral Phosphines. Organometallics 2000, 19, 950-953, doi:10.1021/om990882e.

7. Koshti, V.; Gaikwad, S.; Chikkali, S.H. Contemporary avenues in catalytic PH bond addition reaction: A case study of hydrophosphination. Coord. Chem. Rev. 2014, 265, 52-73, doi:https://doi.org/10.1016/j.ccr.2014.01.006.

8. Bange, C.A. Exploration of Zirconium-Catalyzed Intermolecular Hydrophosphination with Primary Phosphines: Photocatalytic Single and Double Hydrophosphination. Ph.D. Dissertation Thesis, University of Vermont 2018, 1-339.

9. Gladysz, J.A.; Bedford, R.B.; Fujita, M.; Gabbai, F.P.; Goldberg, K.I.; Holland, P.L.; Kiplinger, J.L.; Krische, M.J.; Louie, J.; Lu, C.C.; et al. Organometallics Roundtable 2013-2014. Organometallics 2014, 33, 1505-1527, doi:10.1021/om500253z.

10. King, A.K.; Gallagher, K.J.; Mahon, M.F.; Webster, R.L. Markovnikov versus anti-Markovnikov Hydrophosphination: Divergent Reactivity Using an Iron(II) $\beta$-Diketiminate Pre-Catalyst. Chem. Eur. J. 2017, 23, 9039-9043, doi:https://doi.org/10.1002/chem.201702374.

11. Kamitani, M.; Itazaki, M.; Tamiya, C.; Nakazawa, H. Regioselective Double Hydrophosphination of Terminal Arylacetylenes Catalyzed by an Iron Complex. J. Am. Chem. Soc. 2012, 134, 11932-11935, doi:10.1021/ja304818c.

Bange, C.A.; Waterman, R. Zirconium-Catalyzed Intermolecular Double Hydrophosphination of Alkynes with a Primary Phosphine. ACS Catal. 2016, 6, 6413-6416, doi:10.1021/acscatal.6b01850.

13. Mimeau, D.; Gaumont, A.-C. Regio- and Stereoselective Hydrophosphination Reactions of Alkynes with Phosphine-Boranes: Access to Stereodefined Vinylphosphine Derivatives. J. Org. Chem. 2003, 68, 7016-7022, doi:10.1021/jo030096q

14. Basalov, I.V.; Dorcet, V.; Fukin, G.K.; Carpentier, J.-F.; Sarazin, Y.; Trifonov, A.A. Highly Active, Chemo- and Regioselective YbII and SmII Catalysts for the Hydrophosphination of Styrene with Phenylphosphine. Chem. Eur. J. 2015, 21, 6033-6036, doi:https://doi.org/10.1002/chem.201500380.

15. Rosenberg, L. Mechanisms of Metal-Catalyzed Hydrophosphination of Alkenes and Alkynes. ACS Catal. 2013, 3, 2845-2855, doi:10.1021/cs400685c

16. Wang, C.; Huang, K.; Ye, J.; Duan, W.-L. Asymmetric Synthesis of P-Stereogenic Secondary Phosphine-Boranes by an Unsymmetric Bisphosphine Pincer-Nickel Complex. J. Am. Chem. Soc. 2021, 143, 5685-5690, doi:10.1021/jacs.1c02772. Lapshin, I.V.; Basalov, I.V.; Lyssenko, K.A.; Cherkasov, A.V.; Trifonov, A.A. CaII, YbII and SmII Bis(Amido) Complexes Coordinated by NHC Ligands: Efficient Catalysts for Highly Regio- and Chemoselective Consecutive Hydrophosphinations with PH3. Chem. Eur. J. 2019, 25, 459-463, doi:https://doi.org/10.1002/chem.201804549.

18. Sadeer, A.; Kojima, T.; Ng, J.S.; Gan, K.; Chew, R.J.; Li, Y.; Pullarkat, S.A. Catalytic access to ferrocenyl phosphines bearing both planar and central chirality - A kinetic resolution approach via catalytic asymmetric $\mathrm{P}(\mathrm{III})-\mathrm{C}$ bond formation. Tetrahedron 2020, 76, 131259, doi:https://doi.org/10.1016/j.tet.2020.131259.

19. Isley, N.A.; Linstadt, R.T.H.; Slack, E.D.; Lipshutz, B.H. Copper-catalyzed hydrophosphinations of styrenes in water at room temperature. Dalton Trans. 2014, 43, 13196-13200, doi:10.1039/C4DT00993B. 
20. Li, J.; Lamsfus, C.A.; Song, C.; Liu, J.; Fan, G.; Maron, L.; Cui, C. Samarium-Catalyzed Diastereoselective Double Addition of Phenylphosphine to Imines and Mechanistic Studies by DFT Calculations. ChemCatChem 2017, 9, 1368-1372, doi:10.1002/cctc.201700003.

21. Moglie, Y.; González-Soria, M.J.; Martín-García, I.; Radivoy, G.; Alonso, F. Catalyst- and solvent-free hydrophosphination and multicomponent hydrothiophosphination of alkenes and alkynes. Green Chem. 2016, 18, 4896-4907, doi:10.1039/C6GC00903D.

22. Teo, R.H.X.; Chen, H.J.; Li, Y.; Pullarkat, S.A.; Leung, P.-H. Asymmetric Catalytic 1,2-Dihydrophosphination of Secondary 1,2-Diphosphines - Direct Access to Free $\mathrm{P}^{*}$ - and $\mathrm{P}^{*}, \mathrm{C}^{*}$-Diphosphines. Adv. Synth. Catal. 2020, 362, 2373-2378, doi:https://doi.org/10.1002/adsc.202000131.

23. Garner, M.E.; Parker, B.F.; Hohloch, S.; Bergman, R.G.; Arnold, J. Thorium Metallacycle Facilitates Catalytic Alkyne Hydrophosphination. J. Am. Chem. Soc. 2017, 139, 12935-12938, doi:10.1021/jacs.7b08323.

24. Waterman, R. Triamidoamine-Supported Zirconium Compounds in Main Group Bond-Formation Catalysis. Acc. Chem. Res. 2019, 52, 2361-2369, doi:10.1021/acs.accounts.9b00284.

Trifonov, A.A.; Basalov, I.V.; Kissel, A.A. Use of organolanthanides in the catalytic intermolecular hydrophosphination and hydroamination of multiple C-C bonds. Dalton Trans. 2016, 45, 19172-19193, doi:10.1039/C6DT03913H.

Webster, R.L. $\beta$-Diketiminate complexes of the first row transition metals: applications in catalysis. Dalton Trans. 2017, 46, 4483-4498, doi:10.1039/C7DT00319F.

Dannenberg, S.G.; Waterman, R. A bench-stable copper photocatalyst for the rapid hydrophosphination of activated and unactivated alkenes. Chem. Commun. (Camb) 2020, 56, 14219-14222, doi:10.1039/D0CC06570F.

Sarazin, Y.; Carpentier, J.-F. Calcium, Strontium and Barium Homogeneous Catalysts for Fine Chemicals Synthesis. Chem. Rec. 2016, 16, 2482-2505, doi:https://doi.org/10.1002/tcr.201600067.

Seah, J.W.K.; Teo, R.H.X.; Leung, P.-H. Organometallic chemistry and application of palladacycles in asymmetric hydrophosphination reactions. Dalton Trans. 2021, doi:10.1039/D1DT03134A.

Pullarkat, S.A. Recent Progress in Palladium-Catalyzed Asymmetric Hydrophos-phination. Synth. 2016, 48, 493-503.

Bange, C.A.; Conger, M.A.; Novas, B.T.; Young, E.R.; Liptak, M.D.; Waterman, R. Light-Driven, Zirconium-Catalyzed Hydrophosphination with Primary Phosphines. ACS Catal. 2018, 8, 6230-6238, doi:10.1021/acscatal.8b01002.

Novas, B.T.; Bange, C.A.; Waterman, R. Photocatalytic Hydrophosphination of Alkenes and Alkynes Using Diphenylphosphine and Triamidoamine-Supported Zirconium. Eur. J. Inorg. Chem. 2019, 2019, 1640-1643, doi:10.1002/ejic.201801079.

33. Cibuzar, M.P.; Novas, B.T.; Waterman, R. Zirconium Complexes. In Comprehensive Coordination Chemistry III, Constable, E.C., Parkin, G., Que Jr, L., Eds.; Elsevier: Oxford, 2021; pp. 162-196.

34. Bange, C.A.; Waterman, R. Zirconium-catalyzed hydroarsination with primary arsines. Polyhedron 2018, 156, 31-34, doi:https://doi.org/10.1016/j.poly.2018.09.007.

35. Cibuzar, M.P.; Dannenberg, S.G.; Waterman, R. A Commercially Available Ruthenium Compound for Catalytic Hydrophosphination. Isr. J. Chem. 2020, 60, 446-451, doi:https://doi.org/10.1002/ijch.201900070. Ackley, B.J.; Pagano, J.K.; Waterman, R. Visible-light and thermal driven double hydrophosphination of terminal alkynes using a commercially available iron compound. Chem. Commun. (Camb) 2018, 54, 2774-2776, doi:10.1039/c8cc00847g.

37. Zhang, Y.; Qu, L.; Wang, Y.; Yuan, D.; Yao, Y.; Shen, Q. Neutral and Cationic Zirconium Complexes Bearing Multidentate Aminophenolato Ligands for Hydrophosphination Reactions of Alkenes and Heterocumulenes. Inorg. Chem. 2018, 57, 139149, doi:10.1021/acs.inorgchem.7b02248. 
38. Zhang, Y.; Wang, X.; Wang, Y.; Yuan, D.; Yao, Y. Hydrophosphination of alkenes and alkynes with primary phosphines catalyzed by zirconium complexes bearing aminophenolato ligands. Dalton Trans. 2018, 47, 9090-9095, doi:10.1039/C8DT02122H.

39. Zhang, Y.; Sun, Q.; Wang, Y.; Yuan, D.; Yao, Y.; Shen, Q. Intramolecular hydroamination reactions catalyzed by zirconium 357 complexes bearing bridged bis(phenolato) ligands. RSC Adv. 2016, 6, 10541-10548, doi:10.1039/C5RA23270H.

40. Waterman, R. Selective Dehydrocoupling of Phosphines by Triamidoamine Zirconium Catalyst. Organometallics 2007, 26, 2492-2494, doi:10.1021/om070189o. 